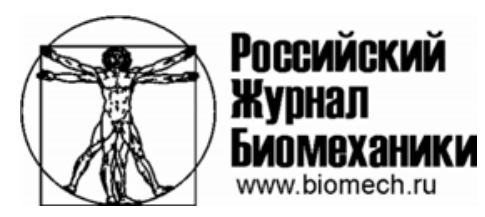

\title{
БИОМЕХАНИЧЕСКИЙ АНАЛИЗ МОСТОВИДНОГО ПРОТЕЗА ДЛЯ ЗАМЕЩЕНИЯ ДЕФЕКТОВ ЗУБНОГО РЯДА, ОСЛОЖНЕННЫХ ВТОРИЧНЫМИ ДЕФОРМАЦИЯМИ
}

\author{
В.А. Тропин ${ }^{1}$, В.А. Лохов ${ }^{1}$, А.В. Старкова ${ }^{2}$, Н.Б. Асташина ${ }^{2}$ \\ ${ }^{1}$ Кафредра теоретической механики и биомеханики Пермского национального исследовательского \\ политехнического университета, Россия, 614990, Пермь, Комсомольский проспект, 29, e-mail: \\ valeriy.lokhov@yandex.ru \\ 2 Кафедра ортопедической стоматологии Пермского государственного медицинского университета \\ им. академика Е.А. Вагнера Минздрава России, 614000, Пермь, ул. Петропавловская, 26, e-mail: \\ starkova.a.v@yandex.ru
}

\begin{abstract}
Аннотация. Предложен несъемно-разборный мостовидный протез для замещения включенного дефекта бокового отдела зубного ряда, осложненного горизонтальными вторичными деформациями. Традиционные конструкции несъемных мостовидных протезов невозможно использовать при наклоне опорных зубов более $30^{\circ}$ без депульпирования и сошлифовывания большого слоя твердых тканей зубов. Данный мостовидный протез дает возможность препарировать опорные зубы с минимальным снятием твердых тканей и исключает их депульпирование. Использование конструкции при конвергенции опорных зубов более $30^{\circ}$ достигается за счет соединения частей несъемно-разборного мостовидного протеза двумя экстракоронарными неактивируемыми рельсовыми замками в виде трубки с силовым креплением и за счет окклюзионной накладки на дистальную опорную коронку, что позволяет равномерно распределять жевательную нагрузку и напряжения в костной ткани. Целью работы являются расчет полей напряжений в протезе при некоторых характерных величинах жевательной нагрузки и оценка необходимой и достаточной прочности материала, используемого в конструкции протеза. В ходе работы была построена трехмерная модель несъемно-разборного мостовидного протеза, замещающего отсутствие первого моляра и второго премоляра, проведены статические расчеты полей напряжений в программном пакете ANSYS, а также показано уменьшение максимальных напряжений при использовании накладки в конструкции протеза.
\end{abstract}

Ключевые слова: несъемно-разборный мостовидный протез, ANSYS, поле напряжений, окклюзионная накладка.

\section{ВвеДЕНИЕ}

Деформация зубных рядов является одним из симптомов частичной потери зубов. Горизонтальные вторичные деформации возникают после потери одного рядом стоящего зуба и более и выявляются при изменении положения зубов, ограничивающих дефект.

\footnotetext{
(C) Тропин В.А., Лохов В.А., Старкова А.В., Асташина Н.Б., 2015

Тропин Василий Андреевич, магистрант кафедры теоретической механики и биомеханики, Пермь Лохов Валерий Александрович, к.ф.-м.н., доцент кафедры теоретической механики и биомеханики, Пермь

Старкова Анна Валерьевна, аспирант кафедры ортопедической стоматологии, Пермь Асташина Наталья Борисовна, д.м.н., доцент кафедры ортопедической стоматологии, Пермь
} 


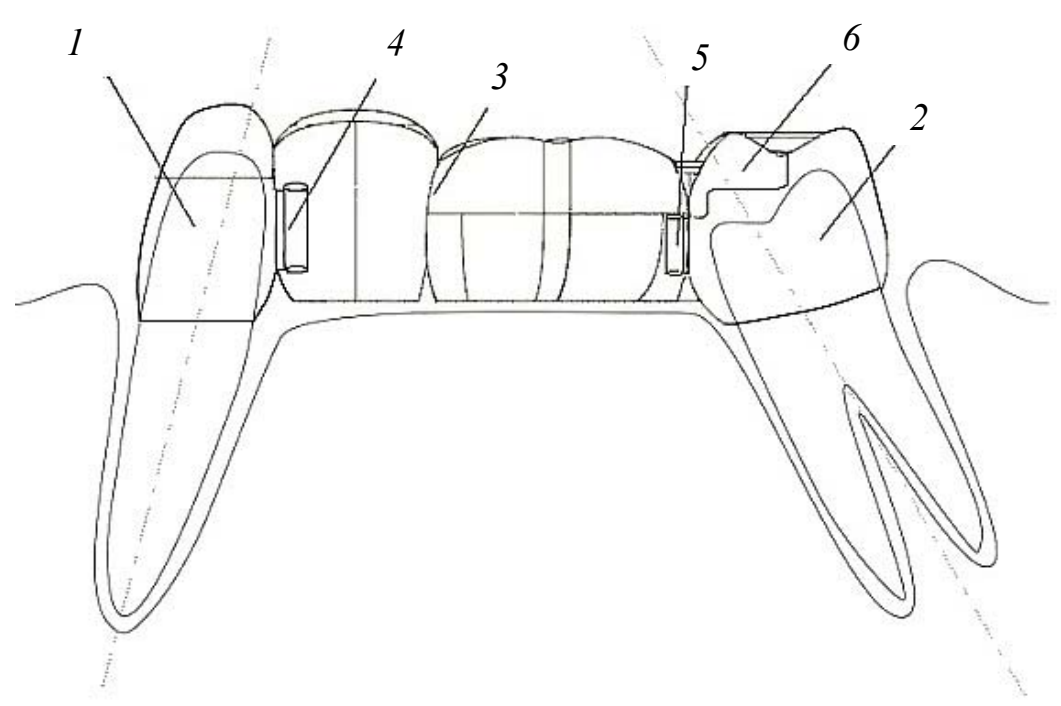

Рис.1. Схема несъемно-разборного мостовидного протеза

В настоящее время для замещения включенных дефектов боковых отделов зубных рядов, осложненных вторичными деформациями, используются различные способы ортопедического лечения: несъемные (мостовидные, адгезивные) и съемные (бюгельные или пластиночные) протезы, а также внутрикостные дентальные имплантаты.

Развитие патологии при дефектах также обусловлено нежелательным полем механических напряжений и может приводить к патологиям других элементов зубочелюстной системы (височно-нижнечелюстной сустав) и других систем организма человека (мозговое кровообращение) [2, 5, 6, 8]. В некоторых случаях полем напряжений можно управлять [9-12]. В любом случае необходимо как можно раньше исправлять патологии зубочелюстной системы.

При отсутствии одного или двух зубов в боковом отделе нижней челюсти, осложненном вторичными деформациями, ортопедическое лечение больных преимущественно осуществляется с помощью традиционных мостовидных протезов $[4,7]$. Их применение при конвергенции опорных зубов более $30^{\circ}$ невозможно без депульпирования и сошлифовывания большого слоя твердых тканей зубов. Учитывая недостатки этих конструкций, был разработан несъемно-разборный мостовидный протез для замещения включенных дефектов в боковых отделах зубных рядов, протяженностью в один или два зуба, осложненных горизонтальными вторичными деформациями [7].

Модель конструкции (рис. 1) представляет собой две опорные коронки $(1,2)$ и промежуточную часть (3). Части несъемно-разборного мостовидного протеза соединены друг с другом посредством двух интракоронковых цилиндрических рельсовых замковых креплений $(4,5)$ и окклюзионной накладки (6) на дистальную опорную коронку. Части несъемно-разборного мостовидного протеза соединяются друг с другом посредством двух экстракоронарных неактивируемых, в виде трубки, рельсовых замковых креплений и окклюзионной накладки на дистальную опорную коронку. Патрицы (внутренняя часть замка, рис. 1, 2) экстракоронарных замков располагаются на медиальной и дистальной коронках опорных зубов, имеющих наклон в сторону дефекта 15 и $35^{\circ}$, а матрицы - в промежуточной части мостовидного протеза. Данный несъемно-разборный мостовидный протез дает возможность:

- препарировать опорные зубы с минимальным снятием твердых тканей и исключает их депульпирование; 


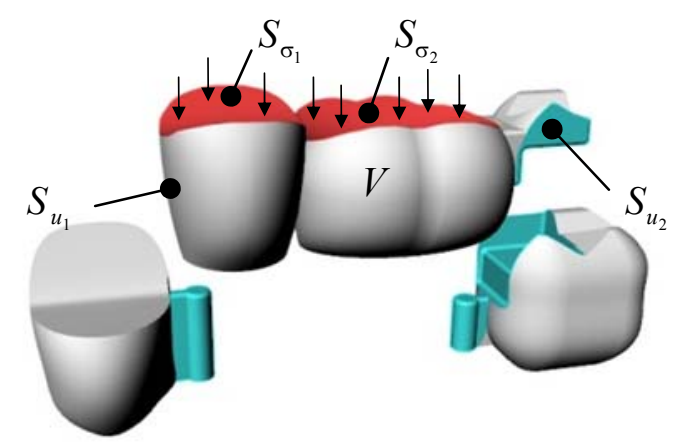

Рис. 2. Расчетная модель мостовидного протеза с накладкой

- использовать конструкции при конвергенции опорных зубов более $30^{\circ}$, что достигается за счет соединения частей несъемно-разборного мостовидного протеза двумя экстракоронарными неактивируемыми рельсовыми замками в виде трубки с силовым креплением;

- равномерно распределять жевательную нагрузку и напряжения в костной ткани за счет окклюзионной накладки на дистальную опорную коронку.

Целью данного исследования явились моделирование, расчет полей напряжений и оценка величины достаточной прочности материала конструкции несъемно-разборного мостовидного протеза, замещающего отсутствие первого моляра и второго премоляра.

\section{ПОСТАНОВКА ЗАДАЧИ}

Для моделирования формы зубного ряда были использованы анатомические данные о форме коронок правых нижних моляров и премоляров [3]. Была создана трехмерная модель несъемно-разборного мостовидного протеза (см. рис. 2), пригодная для расчетов в программном пакете $A N S Y S$.

В данной работе рассчитаны три задачи на прочность элементов протеза. Во всех задачах использована классическая постановка задачи механики упругого изотропного тела, состоящая из уравнений равновесия, геометрических соотношений Коши, закона Гука, граничных условий:

$$
\begin{gathered}
\nabla \cdot \boldsymbol{\sigma}=0, \mathbf{r} \in V, \\
\boldsymbol{\varepsilon}=1 / 2\left(\nabla \mathbf{u}+\nabla \mathbf{u}^{T}\right), \mathbf{r} \in \bar{V}, \\
\boldsymbol{\sigma}=\mathbf{C} \cdot \boldsymbol{\varepsilon}, \mathbf{r} \in \bar{V},
\end{gathered}
$$

где $V$ - область пространства, занятая телом, $\bar{V}=V \cup S$ ( $S$ - граница тела); $\boldsymbol{\sigma}$ симметричный тензор напряжений; $\mathbf{r}$ - радиус-вектор точки; $\boldsymbol{\varepsilon}$ - тензор малых деформаций; $\mathbf{u}$ - вектор перемещений; $\mathbf{C}$ - тензор четвертого ранга упругих модулей.

В задаче материал считается изотропным, тогда в тензор $\mathbf{C}$ входит две независимые величины: модуль Юнга $E$ и коэффициент Пуассона $v$. Протез изготовлен из сплава циркония $[2,3]$ и имеет следующие свойства: модуль упругости $E=99$ ГПа, коэффициент Пуассона $v=0,3$.

Граничные условия представлены на рис 2. Части границы $S_{\sigma_{1}}$ и $S_{\sigma_{2}}$ подвержены равномерному жевательному давлению, действующему вдоль вертикальной оси, границы $S_{u_{1}}$ и $S_{u_{2}}$ жестко закреплены. Для наглядности представления границ $S_{u_{1}}$ и $S_{u_{2}}$ на рис. 2 показаны опорные коронки: 


$$
\begin{aligned}
& \mathbf{n} \cdot \boldsymbol{\sigma}=\mathbf{p}_{1}, \quad \mathbf{r} \in S_{\sigma_{1}}, \\
& \mathbf{n} \cdot \boldsymbol{\sigma}=\mathbf{p}_{2}, \quad \mathbf{r} \in S_{\sigma_{2}}, \\
& \mathbf{u}=0, \quad \mathbf{r} \in S_{u_{1}}, S_{u_{2}} .
\end{aligned}
$$

Было проведено несколько расчетов полей напряжений в элементах крепления на промежуточной части протеза и опорных коронках при разных вариантах нагрузок:

- расчет полей напряжений протеза с накладкой при максимально возможных нагрузках (нагрузка на поверхности $S_{\sigma_{1}}$ равна $10 \mathrm{MПа,} \mathrm{на} \mathrm{поверхности} S_{\sigma_{2}}-9,6 \mathrm{MПа);}$

- расчет полей напряжений протеза с накладкой и без накладки при обычных жевательных нагрузках (нагрузка на поверхности $S_{\sigma_{1}}$ и $S_{\sigma_{2}}$ равна 1,75 МПа);

- расчет максимальных нагрузок на патрице замка (нагрузка на поверхности $S_{\sigma_{3}}$ равна $222 \mathrm{M \Pi а).}$

Во всех расчетах нагрузка прикладывается на жевательные поверхности в виде постоянного давления (см. рис. 2).

\section{РАСЧЕТ ПРИ МАКСИМАЛЬНО ВОЗМОЖНЫХ НАГРУЗКАХ}

В этом расчете определяется необходимая прочность при максимально возможной жевательной нагрузке, ограниченной болевым порогом при отсутствии патологий. Из литературных данных по максимальной силе сжатия парами зубов-антагонистов верхней и нижней челюсти [1] известны данные, указанные в табл. 1. В качестве исходных данных принимаем силы сжатия, действующие на первый моляр и второй премоляр у мужчин, и пересчитываем их с учетом площади жевательной поверхности.

Нагрузки для промежуточной части мостового протеза, используемые в расчете, приведены в табл. 2.

Нагрузки для промежуточной части мостового протеза, полученные в результате расчета, представлены на рис. 3, 4 .

В ходе расчета получены следующие результаты.

На рис. 4, $a$ видно, что интенсивность напряжений на верхнем и нижнем торце матрицы замкового соединения со вторым моляром достигает примерно 140 МПа.

Таблииа 1

Максимальная сила сжатия парами зубов антагонистов

\begin{tabular}{|c|c|c|c|c|}
\hline \multirow{2}{*}{$\begin{array}{c}\text { Группа } \\
\text { испытуемых }\end{array}$} & \multicolumn{4}{|c|}{ Сила сжатия, Н } \\
\cline { 2 - 5 } & Первый премоляр & Второй премоляр & Первый моляр & Второй моляр \\
\hline Мужчины & 400 & 400 & 720 & 680 \\
\hline Женщины & 260 & 260 & 460 & 450 \\
\hline
\end{tabular}

Таблииа 2

Нагрузка для расчета напряжений при максимально возможных нагрузках

\begin{tabular}{|c|c|c|}
\hline Показатель & Второй премоляр & Первый моляр \\
\hline Сила, действующая на жевательную поверхность, Н & 400 & 720 \\
\hline Давление на жевательную поверхность, МПа & 10 & 9,6 \\
\hline
\end{tabular}



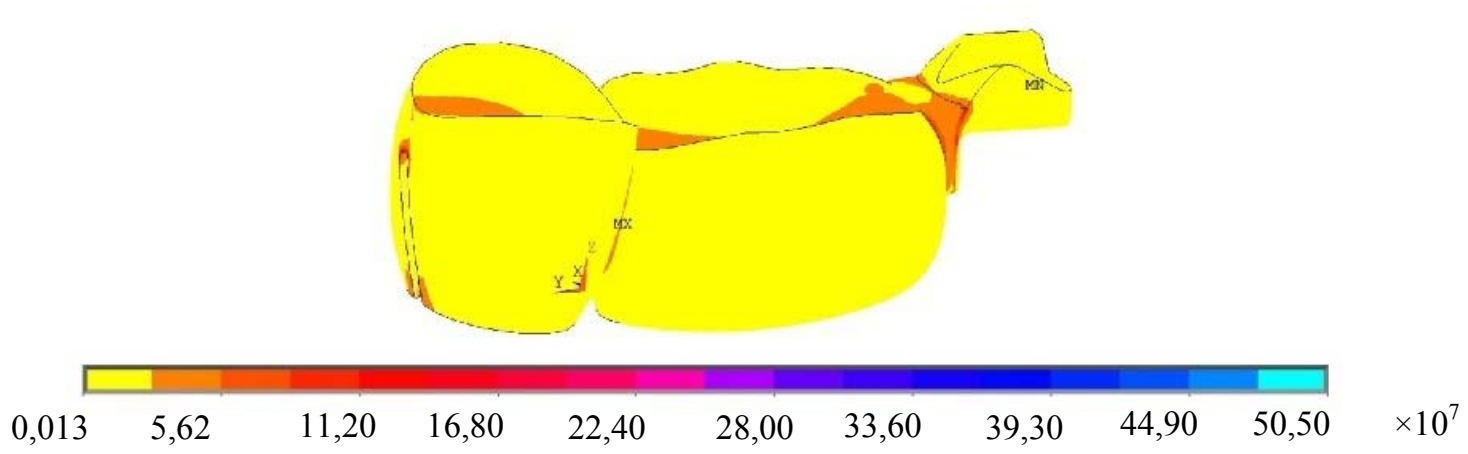

Рис. 3. Интенсивность напряжений на промежуточной части протеза и точка максимума на промежуточной части протеза

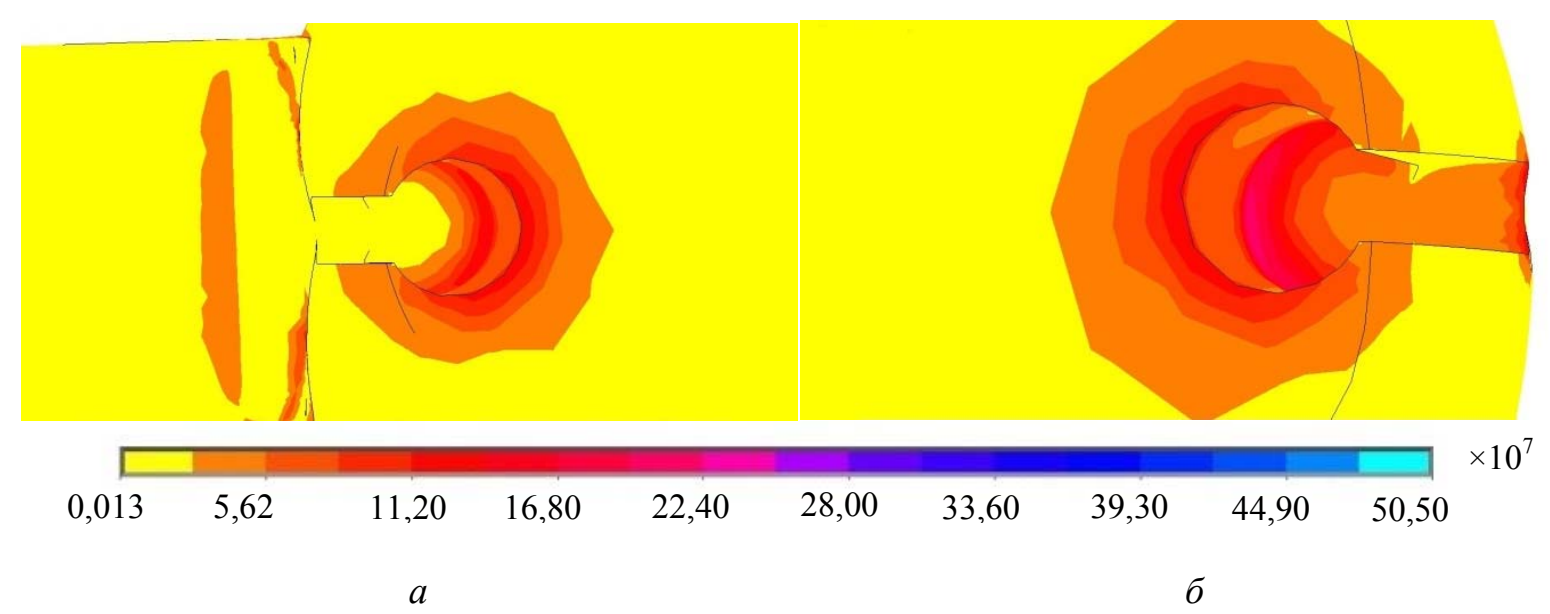

Рис. 4. Концентраторы напряжений при максимальных нагрузках в замковом соединении со вторым моляром и первым премоляром

На рис. 4, б видно, что интенсивность напряжений на верхнем (закругленном) торце матрицы замкового соединения с первым премоляром достигает 230 МПа, на нижнем - 150 МПа.

\section{РАСЧЕТ ПАТРИЦЫ ЗАМКА НА ПРОЧНОСТЬ}

Так как напряжения на замковом соединении с первым премоляром больше, чем со вторым, мы проверили на прочность это соединение. При этом считаем, что нагрузка на крепление не превышает максимальной жевательной нагрузки, равной $200 \mathrm{H}$. Нагрузку прикладывали в виде равномерного давления на плоскости торца патрицы, равного 222 МПа. Тело жестко закреплено на нижней поверхности.

При расчете получили следующие результаты (рис. 5):

- максимальная интенсивность напряжений равна 4,72 МПа, что показывает наличие большого запаса прочности;

- максимум напряжений расположен в концентраторе, образованном прямым углом между поверхностями зуба и торцом патрицы замка, следовательно, можно уменьшить максимальное напряжение, закруглив этот угол. 


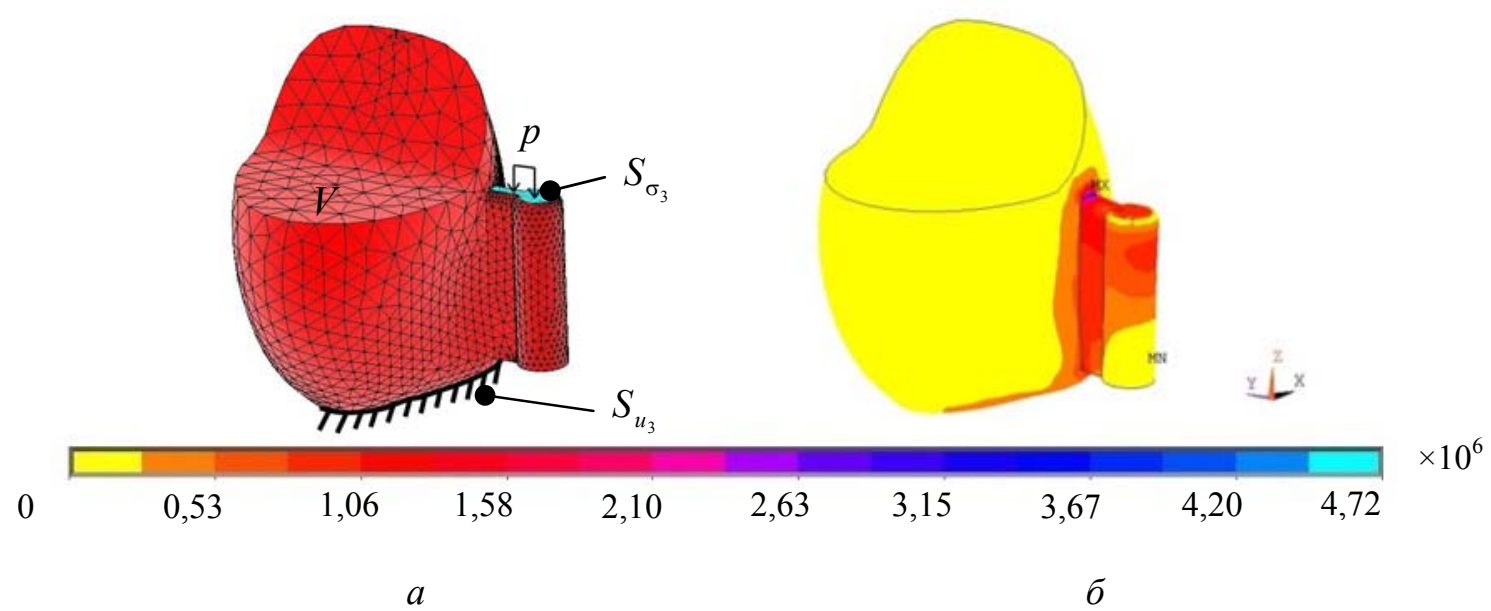

Рис. 5. Расчетная модель соединения с первым премоляром и напряжения, получаемые при нагружении

\section{СРАВНЕНИЕ НЕСЪЕМНО-РАЗБОРНОГО МОСТОВИДНОГО ПРОТЕЗА С НАКЛАДКОЙ И БЕЗ НЕЕ}

Для определения эффективности применения накладки проводили расчет распределения поля напряжений при нормальной жевательной нагрузке. Из экспериментальных данных известно, что суммарная сила, действующая на челюсть при обычном жевании, лежит в пределах 50-200 Н.

Для расчета считали, что жевательная сила равна $200 \mathrm{H}$, сосредоточена на промежуточной части мостового протеза и равномерно распределена по жевательной поверхности в виде давления. При пересчете силы в давление с учетом общей площади жевательной поверхности получили давление, равное 1,75 МПа.

\section{РАСЧЕТ ПАРАМЕТРОВ НЕСЪЕМНО-РАЗБОРНОГО МОСТОВИДНОГО ПРОТЕЗА С НАКЛАДКОЙ И БЕЗ НЕЕ}

В обоих расчетах модель жестко закреплена на поверхности контакта замковых соединений с патрицей замка $\left(S_{u_{1}}\right.$ и $\left.S_{u_{2}}\right)$, в расчете параметров протеза с накладкой в область $S_{u_{2}}$ входят поверхности контакта замкового соединения с патрицей замка и накладки со вторым моляром (рис. 6). На жевательных поверхностях $S_{\sigma_{1}}$ и $S_{\sigma_{2}}$ приложены нагрузки из табл. 3.
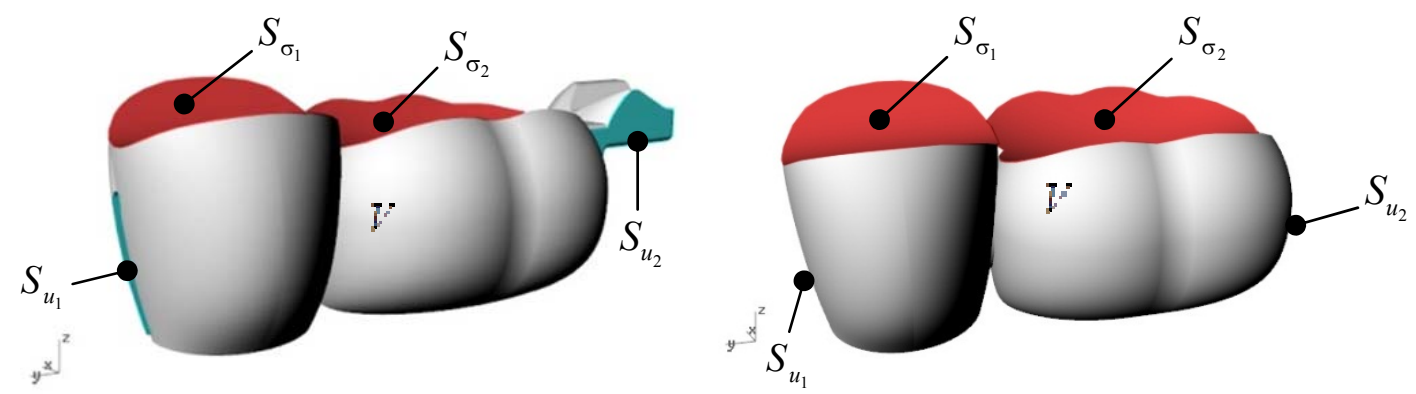

Рис. 6. Граничные условия в расчете параметров протеза с накладкой и без нее 
Значения напряжений в местах их концентраторов, МПа

Таблииа 3

\begin{tabular}{|c|c|c|c|c|}
\hline \multirow{2}{*}{ Протез } & \multicolumn{3}{|c|}{ Верхний концентратор в закреплении } & Нижний концентратор в закреплении \\
\cline { 1 - 5 } & $\begin{array}{c}\text { с первым } \\
\text { премоляром }\end{array}$ & $\begin{array}{c}\text { со вторым } \\
\text { моляром }\end{array}$ & $\begin{array}{c}\text { с первым } \\
\text { премоляром }\end{array}$ & $\begin{array}{c}\text { со вторым } \\
\text { моляром }\end{array}$ \\
\hline С накладкой & 33 & 26 & 29 & 31 \\
\hline Без накладки & 35 & 33 & 29 & 29 \\
\hline
\end{tabular}

В качестве данных для сравнения были выбраны значения напряжений в местах их концентрации. В обоих случаях концентраторы напряжений расположены на верхних и нижних краях замковых креплений. В качестве критерия сравнения принимаем изменение среднего значения напряжений и изменение максимального значения напряжений.

Уровень напряжений в протезе с применением накладки уменьшается на 5,6 \%.

Максимальные напряжения в замковом соединении (с первым премоляром) в протезе с применением накладки уменьшаются на $5,7 \%$, со вторым моляром на $21,2 \%$.

Учитывая, что допустимые напряжения, полученные при статическом расчете, не должны превышать 0,6-0,8 предела прочности материала, испытывающего циклические нагрузки, считаем что допустимый предел прочности материала должен быть не меньше 60 МПа для 10000 циклов нагружения.

\section{РЕЗУЛЬТАТЫ РАБОТЫ}

1) Создана трехмерная модель мостового протеза, пригодная для импортирования в инженерный пакет программ ANSYS;

2) рассчитаны поля напряжений в промежуточной части протеза при максимально возможных нагружениях, ограниченных болевым порогом;

3) рассчитаны поля напряжений в промежуточной части протеза для наиболее нагруженного замкового соединения;

4) показано расположение концентраторов напряжений на поверхности промежуточной части протеза;

5) представлено сравнение распределения напряжений при наличии накладки и ее отсутствии;

6) представленные расчеты показывают максимальные напряжения при разных условиях нагружения и позволяют выбрать материал протеза по его пределу прочности;

7) показана величина снижения значений напряжений в местах их концентрации при использовании накладки на второй моляр в конструкции мостового протеза.

\section{ЗАКЛЮЧЕНИЕ}

Проведенные расчеты позволяют сделать вывод, что конструкция несъемно-разборного мостовидного протеза разработана рационально. Соединение частей конструкции в виде двух экстракоронарных неактивируемых рельсовых замков и окклюзионной накладки на дистальную опорную коронку, выполненную заодно с промежуточной частью несъемно-разборного мостовидного протеза, выполняют функцию распределения жевательной нагрузки, увеличения площади фиксации частей протеза, а также замещения межокклюзионного пространства в области мезиальных 
бугров зубов-антагонистов. Применение данной конструкции при замещении включенных дефектов боковых отделов зубных рядов, осложненных вторичными деформациями, имеет ряд преимуществ перед традиционными мостовидными протезами, которые заключаются в упрощении способа установки несущего элемента, сокращении срока изготовления, высокой эстетике, повышении эффективности функции жевания, уменьшении травматичности для больного, возможности препарирования опорных зубов с минимальным снятием твердых тканей и исключении их депульпирования, использования конструкции при наклоне опорных зубов более $30^{\circ}$.

\section{СПИСОК ЛИТЕРАТУРЫ}

1. Бетельман А.И. Ортопедическая стоматология. - М.: Медицина, 1965. - 411 с.

2. Биомеханические аспекты ортопедического лечения пациентов с патологией зубочелюстной системы: монография / под ред. Г.И. Рогожникова, Ю.И. Няшина, Н.Б. Асташиной, А.Г. Рогожникова, В.М. Тверье. - Пермь: Изд-во Перм. нац. исслед. политехн. ун-та, 2013. $206 \mathrm{c}$.

3. Гайворонский И.В., Петрова Т.Б. Анатомия зубов человека: учеб. пособие. - СПб.: ЭЛБИ-СПб, 2005. - $56 \mathrm{c}$.

4. Жулев Е.Н. Несъемные протезы: теория, клиника и лабораторная техника. - 5-е изд. - М.: Мед. информ. агентство, 2010. - 488 с.

5. Няшин Ю.И., Лохов В.А. Основы биомеханики: учеб. пособие. - Пермь: Изд-во Перм. гос. техн. унта, 2007. $-210 \mathrm{c}$.

6. Няшин Ю.И., Лохов В.А., Тверье В.М., Менар М. Височно-нижнечелюстной сустав человека как элемент зубочелюстной системы: биомеханический анализ // Российский журнал биомеханики. 2009. - T. 13, № 4. - C. 7-21.

7. Старкова А.В., Тропин В.А., Асташина Н.Б. Особенности ортопедического стоматологического лечения пациентов с дефектами зубных рядов, осложненными горизонтальными вторичными деформациями // Использование достижений пермской медицинской науки в практике здравоохраненияя: материалы науч.-практ. конф. молодых ученых в рамках XX междунар. выставки «Медицина и здоровье». - Пермь, 2015. - C. 129-133. DOI: http://dx.doi.org/10.7242/1999$6691 / 2011.4 .3 .32$

8. Трезубов В.Н., Щербаков А.С., Мишнев Л.М., Фадеев Р.А. Ортопедическая стоматология (факультетский курс): учеб. для мед. вузов / под ред. проф. В.Н. Трезубова. - 8 изд-е, перераб. и доп. - СПб: Фолиант, 2010. - 656 с.

9. Туктамышев В.С., Лохов В.А., Няшин Ю.И. Исследование методики независимого управления полными деформациями посредством собственных деформаций в дискретизированных системах // Вычислительная механика сплошных сред. - 2011. - Т. 4, № 3. - C. 110-119. DOI: 10.7242/19996691/2011.4.3.32. DOI: http://dx.doi.org/10.1002/zamm.200510202

10. Туктамышев В.С., Лохов В.А., Няшин Ю.И. Независимое управление напряжениями и деформациями в растущих живых тканях // Российский журнал биомеханики. - 2011. - Т. 15, № 2 (52). - C. 69-76. DOI http://dx.doi.org/10.1007/s00707-004-0191-1

11. Nyashin Y., Lokhov V., Ziegler F. Decomposition method in linear elastic problems with eigenstrain // ZAMM. - 2005. - Vol. 85, № 8. - P. 557-570. DOI: 10.1002/zamm.200510202.

12. Nyashin Y., Lokhov V., Ziegler F. Stress-free displacement control of structures // Acta Mechanica. 2005. - Vol. 175. - P. 45-56. DOI: 10.1007/s00707-004-0191-1.

\section{BIOMECHANICAL ANALYSIS OF THE DENTAL BRIDGE FOR REPLACEMENT OF DENTITION DEFECTS COMPLICATED BY SECONDARY DEFORMITIES}

\section{V.A. Tropin, V.A. Lokhov, A.V. Starkova, N.B. Astashina (Perm, Russia)}

In this paper, we analyzed the parameters of the original design of non-removable bridge for replacement of the defect in side dentition complicated by secondary horizontal 
deformations. Traditional constructions of fixed bridges cannot be used at tilting the abutment teeth more than $30^{\circ}$ without removing of tooth pulp and grinding of a significant layer of hard dental tissues. Application of the proposed construction of a bridge makes it possible to dissect the abutment teeth with minimal removal of hard tissues and eliminates removing of tooth pulp. Using the bridge for tilted abutment teeth with convergence more than $30^{\circ}$ is achieved by connecting the parts of a non-removable bridge by two extra-coronary rail locks in the form of a tube with fastening and also by the occlusal pad at the distal support crown that properly distributes the masticatory loads in the surrounding tissues. The aim of the paper is to calculate the stress fields in the prosthesis at some characteristic masticatory loads and to assess necessary and sufficient strength of the material used for the prosthesis construction. The three-dimensional model was built for non-removable collapsible bridge for replace the missing first molar and second premolar, the static stress fields calculations were performed by the ANSYS software, and also the decrease in maximum stress was shown when using occlusal pad.

Key words: non-removable dental bridge, ANSYS, stress field, oclusal pad.

Получено 14 декабря 2014 